\title{
Bezobjawowy podwójny łuk aorty u 87-letniego pacjenta
}

\section{Asymptomatic double aortic arch in an 87-year-old male}

\author{
Piotr Seiffert ${ }^{1}$, Wojciech Czapla ${ }^{2}$, Dariusz Kucharski ${ }^{3}$ \\ ${ }^{1}$ Oddział Geriatryczny Szpitala Geriatrycznego im. Jana Pawła II w Katowicach \\ ${ }^{2}$ Odział Wewnętrzny Szpitala Miejskiego nr 4 w Gliwicach \\ ${ }^{3}$ Zakład Radiodiagnostyki Szpitala Miejskiego nr 4 w Gliwicach
}

\section{Streszczenie}

Pacjent w wieku 87 lat został przyjęty do szpitala w celu przeprowadzenia diagnostyki omdleń. W przeglądowym zdjęciu rentgenowskim klatki piersiowej stwierdzono wymagające różnicowania zmiany na wysokości łuku aorty. W tomografii komputerowej uwidoczniono podwójny łuk aorty w niewielkim stopniu uciskający tchawicę i modelujący przełyk. Jako przyczynę omdleń zdiagnozowano napadowe migotanie przedsionków. Z powodu braku objawów związanych z podwójnym łukiem aorty zalecono okresową kontrolę lekarską.

Słowa kluczowe: podwójny łuk aorty, pierścień naczyniowy

(Folia Cardiologica 2015; 10, 4: 298-300)

\section{Wstęp}

Podwójny łuk aorty (DAA, double aortic arch) jest wada rozwojową polegającą na podziale aorty wstępującej na dwa łuki obejmujące tchawicę i przełyk, które następnie się łączą, tworząc pojedynczą aortę zstępującą [1]. Anomalię tę zalicza się do tak zwanych pierścieni naczyniowych, które stanowią około $1 \%$ wrodzonych wad serca [2]. W większości przypadków DAA jest diagnozowany prenatalnie lub we wczesnym dzieciństwie ze względu na objawy wynikające z ucisku na tchawice i/lub przełyk [3]. Z tego powodu opisy przypadków u osób starszych bez objawów są rzadkością.

\section{Opis przypadku}

Mężczyzna w wieku 87 lat został przyjęty do szpitala w celu przeprowadzenia diagnostyki omdleń, które miały miejsce 2-krotnie w ostatnich kilku dniach. Był to pacjent po udarze niedokrwiennym lewej półkuli móżdżku i operacyjnym leczeniu zwężonej prawej tętnicy szyjnej wewnętrznej, chorujący na cukrzycę typu 2 i nadciśnienie tętnicze. Wywiad rodzinny w kierunku chorób układu sercowo-naczyniowego nie był obciążony. W badaniu przedmiotowym zwracały uwage głośny szmer skurczowy nad zastawką aorty, a także chód na szerokiej podstawie. W wykonanym przeglądowym zdjęciu rentgenowskim (RTG) klatki piersiowej na wysokości łuku aorty stwierdzono cechy modelowania tchawicy, a także zmianę wymagającą różnicowania. W tomografii komputerowej (ryc. 1, 2) uwidoczniono podwójny łuk aorty - lewy o szerokości do $14 \mathrm{~mm}$, prawy łuk do $26 \mathrm{~mm}$. Pierścień naczyniowy koncentrycznie obejmował tchawice z jej niewielkim uciskiem oraz przełyk, który odcinkowo przemieścił ku przodowi i powodował jego modelowanie z uciskiem. Lewa tętnica szyjna wspólna i lewa tętnica podobojczykowa odchodziły od lewego łuku aorty, natomiast prawa tętnica szyjna wspólna i prawa tętnica podobojczykowa odchodziły samodzielnie, bezpośrednio od prawego łuku aorty, tworząc kolejną współistniejącą anomalię rozwojową w postaci niewytworzenia pnia ramienno-głowowego. Aorta zstępująca przebiegała po prawej stronie kręgosłupa. W badaniu echokardiograficznym 


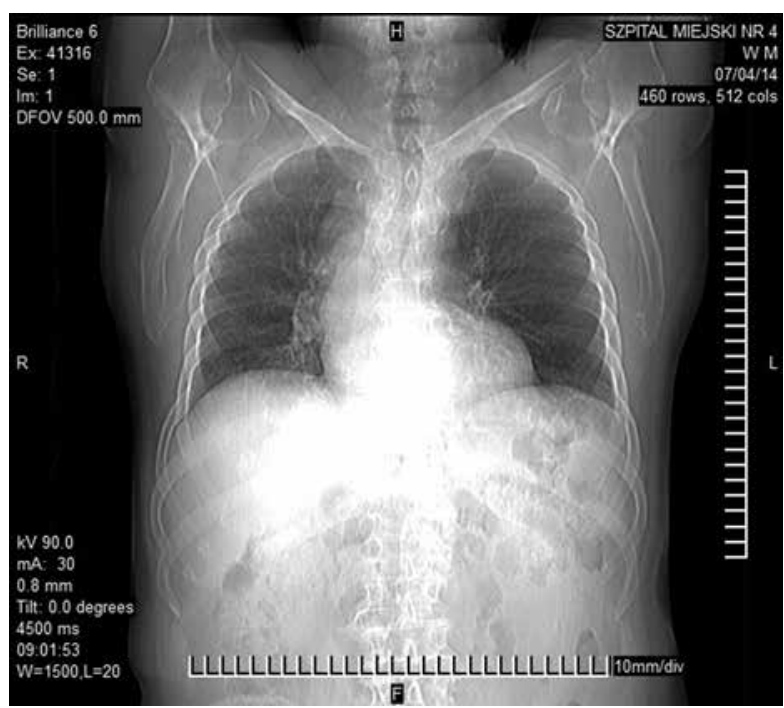

Rycina 1. Topogram badania klatki piersiowej metodą tomografii komputerowej

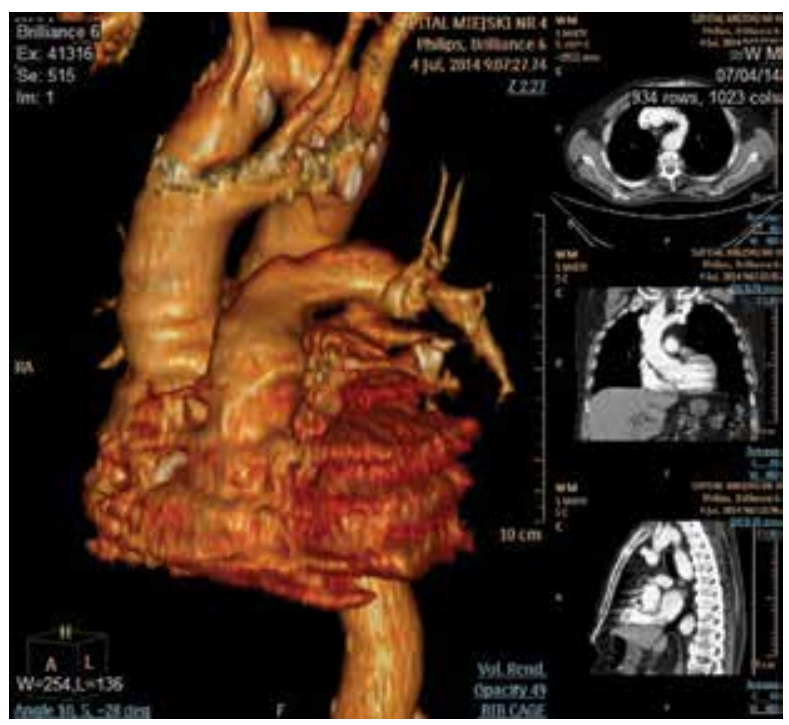

Rycina 2. Obraz tomografii komputerowej w trójwymiarowej (3D) rekonstrukcji objętościowej

stwierdzono miażdżycowe zwyrodnienie zastawki aortalnej z jej łagodnym zwężeniem; gradient maksymalny $21 \mathrm{~mm} \mathrm{Hg}$. Wykonano badanie elektrokardiograficzne (EKG) metoda Holtera, rozpoznając napadowe migotanie przedsionków bez innych zaburzeń rytmu i przewodzenia. Zastosowano leczenie farmakologiczne; nie zaobserwowano ponownych epizodów omdleń. Poinformowano pacjenta o możliwych objawach wynikających z DAA i zalecono okresowe kontrole specjalistyczne.

\section{Dyskusja}

Klasycznie wyróżnia się trzy typy DAA, zależnie od wielkości łuków aorty i cech częściowej atrezji jednego z nich - z do- minującym prawym łukiem (75-90\%), lewym (5-20\%) oraz z równocennością obu łuków (5\%) [4]. U opisywanego pacjenta występował typ z dominacją prawego łuku, bez cech atrezji łuku lewego. Podobnie jak w większości przypadków, u opisywanego pacjenta zaobserwowano ujście prawej tętnicy szyjnej i podobojczykowej bezpośrednio z prawego łuku aorty. Uwage zwracał nietypowy - prawostronny przebieg aorty zstępującej.

Manifestacje kliniczne związane z DAA wynikają z ucisku tchawicy i/lub przełyku przez pierścień naczyniowy. Jeśli występuje ucisk na tchawice, to mogą się pojawić objawy ze strony układu oddechowego. Ma to miejsce zazwyczaj w okresie niemowlęcym lub wczesnodziecięcym [5]. Obraz kliniczny obejmuje duszność, kaszel, stridor, nawracające infekcje układu oddechowego, bezdech i sinicę. U dorosłych pacjentów częściej jednak obserwuje się symptomy ze strony układu pokarmowego związane z uciskiem przełyku, takie jak dysfagia i wymioty. W opisywanym przypadku nie występowały żadne z nich.

W około 20\% przypadków DAA towarzyszą inne wrodzone wady układu sercowo-naczyniowego [6], takie jak tetralogia Fallota czy przełożenie wielkich naczyń, których jednak nie zaobserwowano u opisywanego pacjenta. W badaniu genetycznym osób z prawidłową anatomią serca i DAA w 14\% przypadków stwierdza się delecję 22q11 [7].

Przeglądowe zdjęcie RTG klatki piersiowej u pacjentów z DAA dość często nie wykazuje nieprawidłowości. W pozostałych przypadkach pozwala zaobserwować cechy skrzywienia lub ucisku tchawicy, a także zidentyfikować zarys prawego łuku aorty [8]. W przypadku opisywanego pacjenta zdjęcie wykazało cechy modelowania tchawicy na wysokości łuku aorty, a także - opisaną jako wymagająca różnicowania - zmianę na tej samej wysokości. Zmianę tę, dzięki późniejszej tomografii komputerowej (CT, computed tomography), zinterpretowano jako łuk aorty. W przeszłości za „złoty standard" diagnostyczny uważano wykonanie zdjęcia RTG z przełykiem zakontrastowanym barytem, co w projekcji tylno-przedniej (PA, posteriori-anterior) pozwalało uzyskać obraz obustronnego ucisku przełyku, a w projekcji bocznej - ucisku z tyłu. Diagnostyka echokardiograficzna dorosłych pacjentów często jest trudna; w niektórych przypadkach można zobrazować rozdwojenie aorty, a także dwa tętniące naczynia z przepływem dogłowowym w projekcji nadmostkowej. Dokładną anatomię i lokalizację podwójnego łuku aorty, wraz z jego wpływem na otaczające narządy, można uwidocznić, stosując CT lub rezonans magnetyczny.

W związku ze stosunkowo niewielką częstotliwością występowania podwójnego łuku aorty u dorosłych dotychczas nie opracowano prognoz długoterminowych ani oficjalnych standardów postępowania. U pacjentów z objawami jedyną formą leczenia jest leczenie operacyjne [9]. W opisanym przypadku nie występowały objawy związane z DAA, dlatego przyjęto strategię zachowawczą, zalecając okresowe wizyty kontrolne. 


\section{Podsumowanie}

Bezobjawowy podwójny łuk aorty u dorosłych jest rzadko spotykaną wrodzoną wadą serca, należy jednak o nim pamiętać w praktyce klinicznej, gdyż może stanowić istotny element diagnostyki różnicowej.

\section{Konflikt interesów}

Autorzy deklarują brak konfliktu interesów.

\section{Abstract}

An 87-year-old patient was admitted to hospital for a diagnosis of syncope. Chest radiography showed an image that required a differential diagnosis. Computed tomography revealed a double aortic arch with a slight compression of the trachea and esophagus. Atrial fibrillation was diagnosed as the reason for syncope. The patient was discharged from the hospital with instructions for periodic follow-up.

Key words: double aortic arch, vascular ring

(Folia Cardiologica 2015; 10, 4: 298-300)

\section{Piśmiennictwo}

1. Edwards J. Anomalies of derivatives of the aortic arch system. Med. Clin. North Am. 1948; 32: 925-949.

2. Kouchoukos N.T., Blackstone E.H., Doty D.B. i wsp. Cardiac surgery. 3rd edn. Churchill Livingstone, Elsevier Science, New York/Tokyo 2003.

3. Backer C.L. Compression of the trachea by vascular rings. W: Shields T.W., LoCicero J., Ponn R.B., Rusch V.W. (red.). General thoracic surgery. 6th edn. Lippincott Williams \& Wilkins, Philadelphia 2004: 1083-1099.

4. Rita B., Simone S., Stefano B., Paolo M. Vascular ring due to double aortic arch: a rare cause of dysphagia. Eur. J. Radiol. 2004; 52: 21-24.
5. Kron I.L., Mappin G., Nolan S.P. i wsp. Symptomatic double aortic arch causing tracheal and esophageal compression in the adult. Ann. Thorac. Surg. 1987; 43: 105-106.

6. Emmel M., Schmidt B., Schickendantz S. Double aortic arch in a patient with Fallot's tetralogy. Cardiol. Young 2005; 15: 52-53.

7. McElhinney D.B., Clark B.J., Weinberg P.M. i wsp. Association of chromosome 22q11 deletion with isolated anomalies of aortic arch laterality and branching. J. Am. Coll. Cardiol. 2001; 37: 2114-2119.

8. Lee M.L. Diagnosis of the double aortic arch and its differentiation from the conotruncal malformations. Yonsei Med. J. 2007; 48: 818-826.

9. Alsenaidi K., Gurofsky R., Karamlou T. i wsp. Management and outcomes of double aortic arch in 81 patients. Pediatrics 2006; 118: e1336-e1341.

\section{Komentarz}

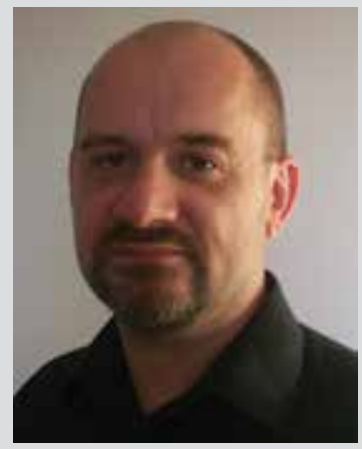

\section{dr n. med. Michał Spałek}

Instytut Nauk Medycznych Wydziału Nauk o Zdrowiu Uniwersytetu Jana Kochanowskiego w Kielcach

Bezobjawowy podwójny łuk aorty (DAA, double aortic arch) jest rzadką wadą sercowo-naczyniową, dlatego opisany przez autorów artykułu przypadek zasługuje na uwagę.

Zwykle wada ta powoduje objawy w wieku wczesnodziecięcym wynikające z ucisku tchawicy i przełyku. W prenatalnym badaniu ultrasonograficznym (USG) można ją rozpoznać już w II trymestrze ciąży, choć u opisywanego pacjenta takiego badania nie można było wykonać z przyczyn oczywistych.

Najczęstszymi objawami DDA są objawy wynikające z ucisku tchawicy - świszczący wydech (stridor), występujący u ponad połowy pacjentów, oraz nawracające infekcje dróg układu oddechowego u około 1/4 pacjentów; rzadszym objawem jest dysfagia wynikająca z ucisku przełyku występująca u około 1/5 pacjentów [1]. Mimo że pacjentów w późnych dekadach życia z nierozpoznanym DDA nie spotyka się często, to można znaleźć opisy takich przypadków w piśmiennictwie - przykładem jest choćby studium przypadku 70-letniej pacjentki opublikowane w „Kardiologii Polskiej” z 2013 roku [2].

Podwójny łuk aorty należy do grupy wad nazywanych pierścieniami naczyniowymi (VR, vascular ring). Po raz pierwszy opisał go w 1737 roku Johann Ludwig Hommel [3]. Pierwszy chirurgiczny podział wad z grupy VR sformułował amery- 
kański chirurg ze szpitala dziecięcego w Bostonie dr Robert E. Gross w 1945 roku [4], a w 1946 roku dr Edward B.D. Neuhauser z tego samego szpitala opisał radiograficzne cechy VR na zdjęciu klatki piersiowej oraz w esofagografii po wypełnieniu przełyku barytem $[4,5]$.

W latach 50. ubiegłego stulecia podstawą diagnostyki obrazowej VR była klasyczna rentgenografia, w kolejnych dwóch dekadach - angiografia, natomiast od lat 80. i 90. XX wieku - badania metodą tomografii komputerowej (CT, computed tomography) i rezonansu magnetycznego. U pacjentów bez objawów obraz badań radiograficznych jest najczęściej prawidłowy [6], dlatego na uwagę zasługuje fakt, że w przypadku prezentowanego chorego na zdjęciu rentgenowskim znaleziono objawy mogące sugerować obecność VR. Choć należy zauważyć, że autorzy nie przedstawiają zdjęcia rentgenowskiego (RTG) klatki piersiowej, a jedynie topogram z badania CT, w którym obraz struktur śródpiersia może być inny niż na zdjęciu RTG klatki piersiowej w projekcji tylno-przedniej (PA, posteriori-anterior), które jest wykonywane w pozycji stojącej.

Wady rozwojowe łuku aorty i gałęzi od niego odchodzących oraz wady rozwojowe pnia płucnego są istotną klinicznie grupą wad rozwojowych układu sercowo-naczyniowego. Mogą one występować jako wady izolowane lub jako złożone zespoły wad serca i dużych naczyń.

Znajomość skomplikowanej i wieloetapowej embriogenezy układu sercowo-naczyniowego pozwala zrozumieć mechanizmy powstawania wad rozwojowych tego układu. Do dokładnej interpretacji wady, lub zespołu wad, konieczna jest znajomość prawidłowej nomenklatury, która pozwala na zrozumiałe dla wszystkich osób zajmujących się ich diagnostyką i leczeniem opisanie znalezionych nieprawidłowości. Do prawidłowej interpretacji na całym świecie jest wykorzystywana sekwencyjna analiza segmentalna $[7,8]$.

Pierwotna cewa sercowa, powstająca z niezróżnicowanych komórek pierwszego i drugiego pola sercowego, ulega w dalszych etapach segmentacji i zapętlaniu. W rozwoju struktur układu sercowo-naczyniowego, poza komórkami pól sercowych, istotne znaczenie mają również grzebienie nerwowe, które biorą udział w powstawaniu tętnic łuków gardłowych, zwojów sercowych, drogi odpływu prawej komory i układu przewodzącego serca. W 4. tygodniu embriogenezy powstaje 6 par łuków gardłowych nazywanych również skrzelowymi lub aortalnymi. Są one zaopatrywane w krew tętniczą z worka aortalnego przez 6 par tętnic, które następnie uchodzą do parzystej aorty grzbietowej, odpowiednio, prawej lub lewej. W czasie embriogenezy piąta para łuków aortalnych zanika. Łuk aorty i odchodzące od niego gałęzie powstają prawidłowo z tętnic trzeciego lewego i czwartego również lewego łuku gardłowego, a przewód tętniczy oraz dalsza część pnia płucnego i lewa tętnica płucna - z tętnicy szóstego lewego łuku gardłowego, natomiast prawa tętnica płucna - z tętnicy bliższej części szóstego prawego łuku aortalnego (ryc. 1).

Leczenia operacyjnego VR wymagają tylko pacjenci z objawami klinicznymi. Ze względu na dość częste współistnienie innych wad serca oraz nieprawidłowości tchawicy i oskrzeli przed zabiegiem wskazane jest wykonie echokardiografii i bronchoskopii.

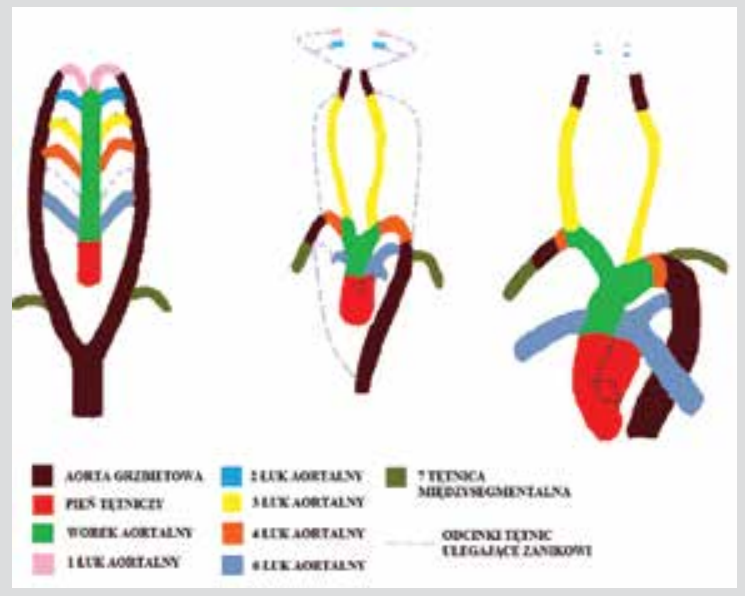

Rycina 1. Rozwój łuku aorty i pnia płucnego u człowieka

\section{Piśmiennictwo}

1. Backer C.L., Ilbawi M.N., Idriss F.S., DeLeon S.Y. Vascular anomalies causing tracheoesophageal compression. Review of experience in children. J. Thorac. Cardiovasc. Surg. 1989; 97: 725-731.

2. Mizia-Stec K., Gieszczyk-Strózik K., Sikora-Puz A. i wsp. Bezobjawowy podwójny łuk aorty u 70-letniej pacjentki. Kardiol. Pol. 2013; 71: 317.

3. Moes C.A.F. Vascular rings and anomalies of the aortic arch. W: Keith J.D., Rowe R.D., Vlad P. (red.). Heart disease in infancy and childhood. Macmillan, New York 1978: 856-881.

4. Gross R.E. Surgical relief for tracheal obstruction from a vascular ring. N. Engl. J. Med. 1945; 233: 586-590.

5. Berdon W.E. Rings, slings, and other things: vascular compression of the infant trachea updated from the midcentury to the millennium - the legacy of Robert E. Gross, MD, and Edward B.D. Neuhauser, MD. Radiology 2000; 216: 624-632.

6. Pickhardt P.J., Siegel M.J., Gutierrez F.R. Vascular rings in symptomatic children: frequency of chest radiographic findings. Radiology 1997; 203: 423-426.

7. Anderson R.H., Shirali G. Sequential segmental analysis. Ann. Pediatr. Cardiol. 2009; 2: 24-35.

8. Niszczota C.S., Koleśnik A. Rozwój i morfologia kliniczna prawidłowego serca płodu i dziecka. Sekwencyjna analiza segmentalna serca z wadą wrodzoną. Pediatr. Pol. 2012; 87: 78-90. 